\title{
Self microemulsifying powder using Aerosil as a carrier
}

\author{
N. Arju, P. K. Bara, M. T. Amin, D. R. Bhowmik and M. S. Hossain* \\ Department of Pharmacy, Noakhali Science and Technology University, Noakhlai-3814, Bangladesh
}

Received: 22 June 2020

Revised: 24 Augugst 2020

Accepted: 31 March 2021

DOI: https://doi.org/10.3329/bjsir.v56i1.54321

\begin{abstract}
This investigation highlighted the development of a solid self micro emulsifying drug delivery system (solid SMEDDS) for improved oral delivery of Valsartan. Liquid SMEDDS were formulated and then the liquid formulation was transformed into free-flowing powder by adsorption on a solid carrier. Here the formulations were prepared in various ratios of the drug to the excipients. Various evaluation studies were performed. In-vitro release profiles of all formulations were evaluated. The concentration of the diffused drug was measured using a UV-visible spectrophotometer at $\lambda \max =250 \mathrm{~nm}$. The faster dissolution was exhibited by the formulations containing Avicel. The experimental results for prepared solid-SMEDDS showed the improved dissolution of the study drug in a short time. F-3 (Assay: 77\%; Dissolution: 51.7\% after $45 \mathrm{~min}, 63 \%$ after $60 \mathrm{~min}$ ) and F-4 (Assay: 63\%; Dissolution: $49.1 \%$ after $45 \mathrm{~min}, 67 \%$ after $60 \mathrm{~min}$ ) showed better evaluation study and this two might be formulated in future. Thus, this study revealed the formulation solid-SMEDDS using Aerosil 200 as an adsorbent with the potential of enhancing the solubility, and dissolution rate of the drug.
\end{abstract}

Keywords: Solid self micro emulsifying drug delivery system; Aerosil; Dissolution rate; Poorly water-soluble drugs

\section{Introduction}

Poor drug bioavailability is a major problem in the present days, frequently faced in the drug development process (Bhagwat and D'Souza, 2012). Orally administered drugs go through a dissolution process and then permeate across the gastric membrane before they can appear in the bloodstream. The solubility of the drug in gastric media is a major problem with most drugs (Savjani et al., 2012). Nowadays about $35-40 \%$ of new drug candidates are poorly water-soluble and oral delivery of such drugs is associated with the difficulty of low bioavailability (Rawat et al., 2014). This is a great challenge for pharmaceutical scientists to convert these lipophilic that means poorly water-soluble drugs into sufficient bioavailable orally administered drugs (Bhagwat and D'Souza, 2012). To overcome these problems various formulation strategies have been applied like complexation, particle size reduction, use of lipids, surfactants, cyclodextrins, and micelles. Advanced approaches include self micro emulsifying drug delivery systems and self micro emulsifying nanoparticles (Rawat et al., 2014; Venkatesan et al., 2005).

Self-emulsifying drug delivery systems are generally isotropic mixtures of drug, lipids, and surfactants, usually with one or more hydrophilic cosolvents or emulsifiers with droplet size ranging from few nanometers to several microns. Self -micro emulsifying drug delivery system is a mixture of natural or synthetic oils, solid or liquid surfactants with droplet size in a range of 10-100nm (Rawat et al., 2014; Tan et al., 2013).

The Biopharmaceutical Classification System (BCS) divides drugs into four classes according to their solubility and 
permeability (Sharma et al., 2009). Valsartan, an Angiotensin II Receptor Antagonist, which is used in the prevention and treatment of Hypertension (Abraham et al., 2011) belongs to class II drug in BCS classification indicates high permeability and low solubility (Moore and Wildfong, 2009; Jinno et al., 2006). The foremost problem with this drug is its low solubility in biological fluids, resulting in poor bioavailability after oral administration. Thus increasing aqueous solubility and dissolution of Valsartan is the main concern.

Present study is aimed towards development of solid self-micro emulsifying drug delivery system (SMEDDS) of Valsartan by adsorption technique using Aerosil 200 as a solid carrier for enhanced bioavailability.

\section{Materials and method}

\section{Materials}

Valsartan - which was a generous gift from Eskayef Pharmaceuticals Ltd., Bangladesh; Tween 80 used as surfactants (Merck kGaA Company, Darmstadt, Germany); Chremophore EL used as co-surfactant (Jiangsu Maoheng Chemical Co; Ltd; Jiangsu, China); Aerosil 200 used as solid carrier (ALPHA CHEMIKA, Mumbai, India); Avicel PH101 used as dissolution enhancer (Shanghai Honest Chem. Co; Ltd; Shanghai, China); Methanol (Fisher Scientific U.K. Limited); Distilled water (supplied from lab).

\section{Methods}

In this method, firsty Valsartan $(50 \mathrm{mg})$ was placed in a glass vial. To this, Chremophore EL was added and warmed in a water bath. Then Tween 80 was added with it and the whole ingredients were mixed gently by stirring in vortex mixture until Valsartan was completely dissolved. Then the mixture added with Aerosil 200 in a proportion of $1: 1$. In these cases, the mixture added dropwise over Aerosil 200 contained in a broad porcelain dish. After each drop, the mixture was homogenized using a glass rod to ensure uniform distribution of formulation. If any damp mass formed they were passed through sieve no. 100 to produce the free-flowing powder.

Four formulations (F1-F4) have been prepared and tabulated as follows:

\section{Characterization of self micro emulsifying drug delivery system}

Various characterization methods have been used to test self micro emulsifying powder (SMEP) to evaluate the change of solubility of the drug.

\section{Angle of repose}

The angle of repose was measured by the fixed funnel method (More and Hazare, 2004; Sun, 2016)

Angle of repose, $\theta=\tan ^{-1}(\mathrm{~h} / \mathrm{r})$

Where $\mathrm{h}$ is the height of heap and $\mathrm{r}$ is the radius heap in the bottom

\section{Bulk density (BD) and tapped density (TD)}

Bulk and tapped density can be easily calculated by pouring a weighed quantity of powder into a calibrated cylinder and measuring its volume (bulk volume), then tapped for the recommended number of times and then again the volume re-measured (tapped volume) (Huang, 2015). After that, the decreased volume was noted to find out tapped density. Bulk density and tapped density can be calculated using the following formulas (Sun, 2016).

Bulk density, BD $=\quad \frac{\text { Weight of powder }}{\text { Volume of packing }}$
Tapped density, TD $=\frac{\text { Weight of powder }}{\text { Tapped volume of packing }}$

\section{Hausner ratio}

The Hausner ratio is calculated by the formula

$\mathrm{H}=\frac{\mathrm{TD}}{\mathrm{BD}}$

Carr's index

The Carr's compressibility index (CI\%) is a measure of powder bridge strength and stability. The Carr's Index is calculated as

Carr's compressibility index $(\%)=\frac{(\mathrm{TD}-\mathrm{BD})}{\mathrm{T} \mathrm{D}} \times 100$

Assay

The main purpose of assay is to show whether the test substances are equally potent as the standard drugs. A standard curve was drawn to compare the sample with the standard (Fig. 1).

\section{Visual inspection of emulsion}

Visual inspection was performed to observe the elegancy of the formulations. 


\section{Dissolution study}

The dissolution of Valsartan from various formulations was studied in $900 \mathrm{ml} 0.1 \mathrm{~N} \mathrm{HCl}$ at $37{ }^{\circ} \mathrm{C}$ using USP dissolution test apparatus II employing paddle stirrer at $70 \mathrm{rpm}$ for 60 min. A sample of SMEP formulation equivalent to $10 \mathrm{mg}$ of Valsartan was used in each test. At predetermined time intervals, $5 \mathrm{ml}$ of the sample was withdrawn using a syringe fitted with a prefilter and simultaneously replacing with fresh $5 \mathrm{ml}$ dissolution fluid. These collected samples were analyzed for Valsartan content measuring the absorbance at $250 \mathrm{~nm}$ (Redasani et al., 2011). Percent of Valsartan dissolved at various time intervals was calculated and plotted against time.

\section{Results and discussion}

Four SMEP formulations of Valsartan were prepared using carriers Aerosil, surfactant Tween 80, co-surfactant Chremophore EL, and Avicel in a different ratio. These formulations were denoted as F-1, F-2, F-3 and F-4. Almost all the formulations prepared were found to be fine and free-flowing powders.

\section{Characterization of SMEP}

SMEP was evaluated to find out flow property and other properties of the powder. So, in this experiment various parameters like Angle of Repose, Bulk density and Tapped density, Hausner Ratio, Carr's Compressibility Index, Assay, Visual inspection of emulsion and dissolution study test hence evaluated.

\section{Determination of flow property of powders}

\section{Angle of repose}

A value of $<30^{\circ}$ indicates 'excellent' flow whereas $>56^{\circ}$ indicates 'very poor' flow. The intermediate scale indicates 'good' ( $\theta$ between $\left.31-35^{\circ}\right)$, 'fair' ( $\theta$ between 36-40 $)$, 'passable which may hang up' $\left(\theta\right.$ between $\left.41-45^{\circ}\right)$, and 'poor which must be agitated or vibrated' ( $\theta$ between $46-55^{\circ}$ ) (USP, 2007). The angles of the four formulations are almost the same though it has bitless deviation. The least value of F-2 indicates the best flow among others and it is 27.290. The value of F-1 (35.370) indicates the fair flow (Table-II). But the other three formulations are within the range of excellent flow. F-3 and F-4 contain Avicel but F-1 and F-4 do not. F-1

Table I. Amount of API and excipients in various ratios

\begin{tabular}{ccccccc}
\hline $\begin{array}{c}\text { Sl. } \\
\text { No. }\end{array}$ & Formulation & $\begin{array}{r}\text { Drug } \\
(\mathrm{mg})\end{array}$ & Chremophore EL (g) & $\begin{array}{c}\text { Tween } \\
(\mathrm{g})\end{array}$ & Avicel PH101(g) & Aerosil (g) \\
\hline 1 & F-1 & 50 & 2.5 & 1.0 & 0.0 & 3.5 \\
2 & F-2 & 50 & 3.0 & 1.0 & 0.0 & 4.0 \\
3 & F-3 & 50 & 3.0 & 1.5 & 0.5 & 5.0 \\
4 & F-4 & 50 & 2.5 & 1.0 & 0.5 & 4.0 \\
\hline
\end{tabular}

Table II. All parameters of powder characteristics

\begin{tabular}{cccccc}
\hline Formulation & $\begin{array}{c}\text { Angle of } \\
\text { repose ( })\end{array}$ & Bulk density & $\begin{array}{c}\text { Tapped } \\
\text { density }\end{array}$ & Hausner ratio & Carr's compressibility index \\
\hline F-1 & 35.37 & 0.050 & 0.058 & 1.16 & 13.8 \\
F-2 & 27.29 & 0.057 & 0.071 & 1.25 & 19.7 \\
F-3 & 28.81 & 0.057 & 0.074 & 1.29 & 23 \\
F-4 & 29.68 & 0.050 & 0.060 & 1.20 & 17 \\
\hline
\end{tabular}


containing Chremphore EL 2.5g and Aerosil 3.5g has more angle of repose than F-2 containing more Chremophore EL $3.0 \mathrm{~g}$ and Aerosil 4.0g (Table- I).

\section{Bulk density and tapped density}

The inter particulate interactions influencing the bulking properties of a powder are also the interactions that interfere with powder flow, a comparison of the bulk and tapped densities can give a measure of the relative importance of these interactions in a given powder. Interestingly, bulk density of F-1 and F-4 are the same as the value 0.050 where the value of other two formulations F-2 and F-3 are the same as 0.057 (Table -II). F-1 and F-4 provide the same bulkiness which is more than the other two formulations. More bulkiness indicates more inter particular space of the powders.

Dramatically the tapped density of F-1 and F-4 are the same and it is 0.058 and 0.060 respectively. In the same way as bulk density, the tapped density of F-2 and F-3 are near the same with the value 0.071 and 0.074 respectively (Table - II) that give a hint of less inter particular space.

\section{Hausner ratio}

A Hausner ratio (HR) of $<1.11$ is considered 'excellent' flow whereas HR $>1.60$ is considered 'very poor' flow. There are intermediate-scales for HR: between 1.12-1.18 is considered 'good' flow; between 1.19-1.25 is considered 'fair' flow, HR between 1.26-1.34 is considered passable flow; between $1.35-1.45$ is considered 'poor' flow, and between 1.46-1.59 is considered 'very poor' flow (Hausner, 1967).

Formulation F-3 showed more HR (1.29) which is passable (Table -II). The other three formulations have good flow property. F-3 contains more Tween $(1.5 \mathrm{gm})$ than the other 3 formulations (Table $-\mathrm{I}$ ) which may be responsible for its poor flowability.

\section{Carr's Compressibility Index}

A Carr's CI of $<10$ is considered 'excellent' flow whereas CI $>38$ is considered 'very poor' flow. There are intermediate-scales for $\mathrm{CI}$ : between $11-15$ is considered 'good' flow; between 16-20 is considered 'fair' flow; between 21-25 is considered passable flow; between 26-31 is considered 'poor' flow, and CI between $32-37$ is considered 'very poor' flow (Carr, 1965). Formulation F-3 is slightly poor flowable but the other three formulations are fairly flowable (Table-II). F-3 containing more Tween (1.5gm) (Table-I) may decrease the flow ability.
Assay

The standard curve of Valsartan is shown in Fig. 1. From the standard curve, we found $\mathrm{R}^{2}=0.9938$ which is near to 1 . We can say that the sample is as potent as the standard.

Four formulations were prepared. From each formulation, we took an equal amount of powder and then dissolved it into methanol and filtered. After that, we checked the assay of the formulations.

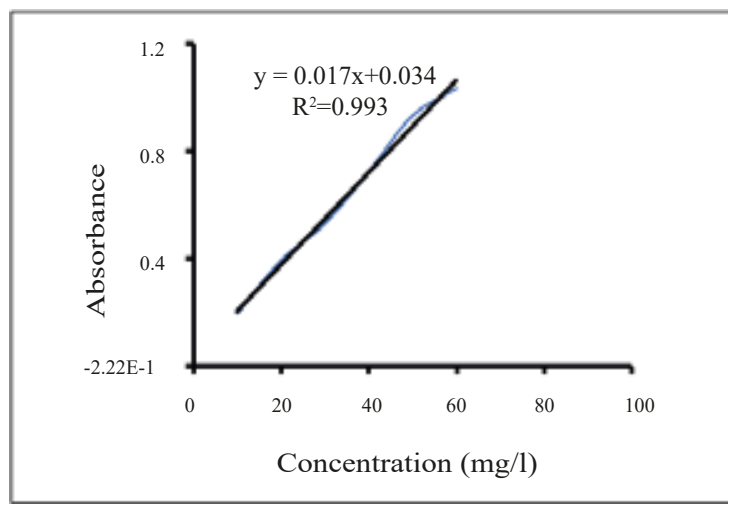

Fig. 1. Standard curve of Valsartan

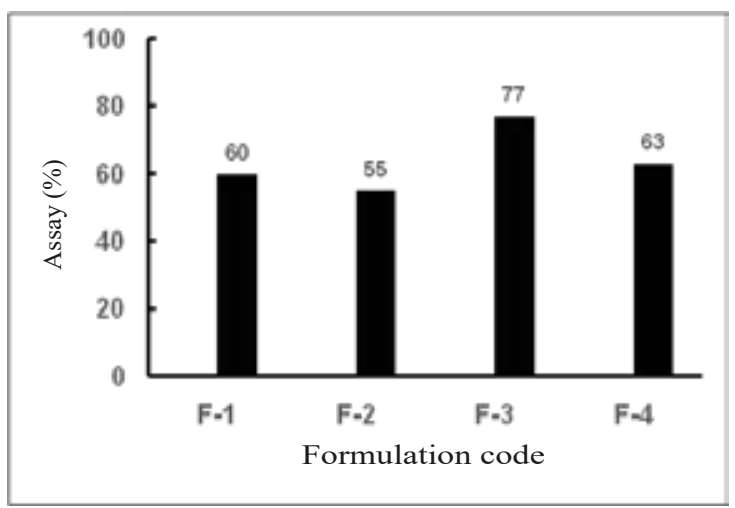

Fig. 2. Assay of the formulations

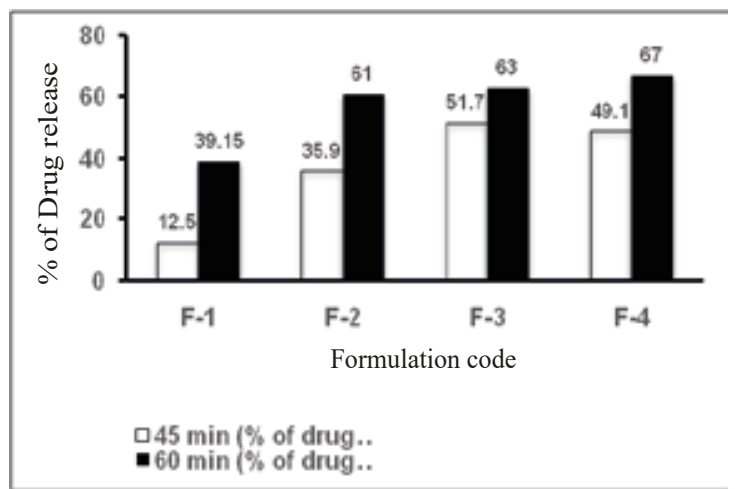

Fig. 3. Dissolution study of drug after specific time interval 
From Fig-3 we can see the first two formulations have less potency than the other two. Formulations F-3 and F-4 contain Avicel which is a dissolution enhancer (Table -I). We can say that due to the presence of Avicel the release of formulations has increased. That's why the potency of formulations F-3 and F-4 is more than F-1 and F-2.

\section{Visual inspection of emulsion}

Formulation F-1 and F-2 are transparent while F-3 and F-4 are opaque.

A visual test was carried out to find out self emulsification of S-SMEDDS in $100 \mathrm{ml}$ double distilled water at $37{ }^{\circ} \mathrm{C}$ under gentle agitation (Bhagwat and D'Souza, 2012). From the formulations, we can see that F-1 and F-2 donot show micro emulsification and thus clear, but F-3 and F-4 are opaque as they contain Avicel PH 101 forming microemulsion spontaneously.

\section{Dissolution study test}

The dissolution study of the pure drug and carrier are presented below.

From Fig. 3, we can see that after 45 min 12.5\% drug and after 60 min $39.15 \%$ drug was released from F-1. Less amount of Chremophore EL (2.5g) (Table -I) may decrease its dissolution and $35.9 \%$ drug was released after $45 \mathrm{~min}$ and $61 \%$ drug was released after $60 \mathrm{~min}$ from the F-2. 51\% released after $45 \mathrm{~min}$ and $63 \%$ released after $60 \mathrm{~min}$ from the F-3 and $49.1 \%$ released after $45 \mathrm{~min}$ and $67 \%$ released after 60 min from the F-4.

In USP release of Valsartan after $30 \mathrm{~min}$ is not less than $80 \%$ (USP 2007). Here the release of drugs is less may be for the use of polymers (Table $-\mathrm{I})$.

The release of drugs from F-3 and F-4 is comparatively more than the other two formulations due to the presence of Avicel which is a dissolution enhancer (Table $-\mathrm{I}$ ).

\section{Conclusion}

The data generated from this experiment showed that preparing solid SMEDDS of Valsartan using Avicel strongly improves the solubility and dissolution profile of the drug. Formulations of drug-containing dissolution enhancer polymer improve the drug release pattern and the problem of efficiently delivering Valsartan which is a poorly water-soluble drug could be solved by lipid-based drug delivery system.

\section{References}

Abraham I, MacDonald K, Hermans C, Aerts A, Lee C, Brié $\mathrm{H}$ and Vancayzeele S (2011), Real-world effectiveness of valsartan on hypertension and total cardiovascular risk: review and implications of a translational research program, Vasc Health Risk Manag. 7: 209-235. DOI: 10.2147/VHRM.S9434

Bhagwat DA and Souza JID (2012), Formulation and evaluation of solid self micro emulsifying drug delivery system using aerosil 200 as solid carrier, Int Curr Pharm J 1(12): 414-419. DOI: org/10.3329/icpj.v1i12.12451

Carr RL (1965), Evaluating flow properties of solids, Chem Engg. 72: 69

Hausner HH (1967), Friction conditions in a mass of metal powder, Int J Powder Metallurgy. 3(4): 7-13.

Huang Z, Scicolone JV, Han X and Davé RN (2015), Improved blend and tablet properties of fine pharmaceutical powders via dry particle coating, Int $J$ Pharm. 478(2): 447-455. DOI: org/10.1016/j.ijpharm.2014.11.068

Jinno JI, Kamada N, Miyake M, Yamada K, Mukai T, Odomi $\mathrm{M}$ and Kimura $\mathrm{T}$ (2006), Effect of particle size reduction on dissolution and oral absorption of a poorly water soluble drug, cilostazol, in beagle dogs, J Control Release. 111(1-2): 56-64. DOI: org/10.1016/j.ijpharm.2014.11.068

Moore MD and Wildfong PL (2009), Aqueous solubility enhancement through engineering of binary solid composites: pharmaceutical applications, J Pharm Innov. 4(1): 36-49.

More HN and Hazare AA (2004), Practical pharmaceutics (Physical pharmacy). ManasPrakashan, Kolhapur, pp 86-105.

Rawat S, Derle DV, Parve BS and Shinde PR (2014), Self Emulsifying Drug Delivery System (SEDDS): A Method for Bioavailability Enhancement, Int J Pharm Chem Bio Sci. 4(3): 479-494.

Redasani VK, Patel PV and Surana SJ (2011), Spectrophotometric method for simultaneous estimation of Valsartan and Hydrochlorothiazide in 
combined tablet dosage form, Der Sinica 2 (3): 123-130.

Savjani KT, Gajjar AK and Savjani JK (2012), Drug solubility: importance and enhancement techniques, ISRN Pharmaceutics 2012. DOI: $10.5402 / 2012 / 195727$

Sharma D, Soni M, Kumar S and Gupta GD (2009), Solubility enhancement-eminent role in poorly soluble drugs, Res J Pharma Technol. 2(2):220-224.

Sun CC (2016), Quantifying effects of moisture content on flow properties of microcrystalline cellulose using a ring shear tester, Powder Technol. 289: 104-108. DOI: org/10.1016/j.powtec.2015.11.044
Tan A, Rao S and Prestidge CA (2013), Transforming lipid-based oral drug delivery systems into solid dosage forms: an overview of solid carriers, physicochemical properties and

biopharmaceutical performance, Pharma Res. 30(12): 2993-3017.

Venkatesan N, Yoshimitsu J, Ito Y, Shibata N and Takada K (2005), Liquid filled nanoparticles as a drug delivery tool for protein therapeutics, Biomaterials. 26(34): $7154 \quad-7163$. DOI: org/10.1016/j. biomaterials. 2005.05 .012 